\title{
Homa-adiponectin index as useful surrogate marker in the screeening of insulin resistance
}

\author{
Brunna Sullara Vilela*, Ana Carolina Junqueira Vasques, Roberta Soares Lara Cassani, Adriana Costa e Forti, \\ José Carlos Pareja, Marcos Antônio Tambascia; Investigators BRAMS, Bruno Geloneze*
}

From 20th Brazilian Diabetes Society Congress

Porto Alegre, Brazil. 11-18 November 2015

\section{Background}

The major adverse consequences of obesity are associated with the development of insulin resistance (IR) and adiposopathy. The Homeostasis Model AssessmentAdiponectin (HOMA-AD) was proposed as a modified version of the HOMA-IR, which incorporates adiponectin in the denominator of the index.

\section{Objectives}

Evaluate the performance of the HOMA-AD compared with the HOMA-IR as a surrogate marker of IR in women, and to establish the cutoff value of the HOMA-AD.

\section{Materials and methods}

The BRAMS is a cross-sectional multicenter survey. The data from 1.062 subjects met the desired criteria: 18-65 yrs. old, BMI: $18.5-49.9 \mathrm{Kg} / \mathrm{m}^{2}$ and non-diabetic. The IR was assessed by the indexes HOMA-IR and HOMA-AD (total sample) and by the hyperglycemic clamp $(n=49)$. Metabolic syndrome was defined using the IDF criteria.

\section{Results}

For the IR assessed by the clamp, the HOMA-AD demonstrated a stronger coefficient of correlation $(r=-$ 0.64) compared with the HOMA-IR $(r=-0.56) ; \mathrm{p}<0.0001$. In the ROC analysis, compared with the HOMA-IR, the HOMA-AD showed higher values of the AUC for the identification of IR based on the clamp test (AUC: 0.844 vs. AUC: 0.804 ) and on the metabolic syndrome (AUC: 0.703 vs. AUC: 0.689 ), respectively; $\mathrm{p}<0.001$ for all. However, the pairwise comparison did not suggest superiority for the HOMA-AD in the diagnostic of IR ( $>>0.05)$. The

\footnotetext{
* Correspondence: brunna_vilela@yahoo.com.br
}

Universidade Estadual de Campinas, Campinas, Brazil optimal cutoff identified for the HOMA-AD for the diagnosis of IR was 0.51 .

\section{Conclusions}

HOMA-AD was demonstrated to be a useful surrogate marker for detecting IR among adult women and presented a similar performance as the HOMA-IR.

Published: 11 November 2015

doi:10.1186/1758-5996-7-S1-A135

Cite this article as: Vilela et al: Homa-adiponectin index as useful surrogate marker in the screeening of insulin resistance. Diabetology \& Metabolic Syndrome 2015 7(Suppl 1):A135. and take full advantage of:

- Convenient online submission

- Thorough peer review

- No space constraints or color figure charges

- Immediate publication on acceptance

- Inclusion in PubMed, CAS, Scopus and Google Scholar

- Research which is freely available for redistribution

Submit your manuscript at www.biomedcentral.com/submit 